\title{
Comparison of Hemodynamic Responses Associated with Tracheal Intubation under Various Induction Doses of Remifentanil and Propofol
}

\author{
Toru Goyagi", Masashi Yoshimoto \\ Department of Anesthesia and Intensive Care Medicine, Graduate School of Medicine, Akita University, Akita, Japan. \\ Email: *tgoyagi@doc.med.akita-u.ac.jp
}

Received June $23^{\text {rd }}, 2012$; revised July $25^{\text {th }}, 2012$; accepted August $16^{\text {th }}, 2012$

\begin{abstract}
Background: The optimal dose of propofol and remifentanil induction to minimize the cardiovascular response associated with tracheal intubation may exist. We investigated the cardiovascular response associated with tracheal intubation when various continuous induction doses of remifentanil in combination with propofol were used. Methods: Seventyfive patients were randomly allocated into 1 of 3 groups: the R-0.4 P-1 group (remifentanil $0.4 \mu \mathrm{g} / \mathrm{kg} / \mathrm{min}$ and propofol $1 \mathrm{mg} / \mathrm{kg}$ ); the R-0.5 P-1 group (remifentanil $0.5 \mu \mathrm{g} / \mathrm{kg} / \mathrm{min}$ and propofol $1 \mathrm{mg} / \mathrm{kg}$ ); and the R-0.4 P-2 group (remifentanil $0.4 \mu \mathrm{g} / \mathrm{kg} / \mathrm{min}$ and propofol $2 \mathrm{mg} / \mathrm{kg}$ ). One minute after remifentanil infusion commenced, a bolus of propofol was injected. Rocuronium $1 \mathrm{mg} / \mathrm{kg}$ was administered $1 \mathrm{~min}$ after propofol injection following loss of consciousness. Controlled ventilation was then performed for $2 \mathrm{~min}$, and the trachea was intubated $4 \mathrm{~min}$ after the start of the remifentanil infusion. The infusion rate of remifentanil was decreased to $0.1 \mu \mathrm{g} / \mathrm{kg} / \mathrm{min}$ after intubation. Blood pressure (BP) and heart rate (HR) were measured during this period until 5 min after tracheal intubation. Results: The changes in BP response due to tracheal intubation in the R-0.4 P-1 group were greater than those in the other 2 groups, whereas the HR responses to tracheal intubation were similar among the 3 groups. Conclusion: The combination of remifentanil 0.4 $\mu \mathrm{g} / \mathrm{kg} / \mathrm{min}$ and propofol $1 \mathrm{mg} / \mathrm{kg}$ led to an exaggerated cardiovascular response to tracheal intubation compared with the other combination groups.
\end{abstract}

Keywords: Remifentanil; Propofol; Tracheal Intubation; Presser Response

\section{Introduction}

Increased blood pressure and tachycardia associated with tracheal intubation could cause detrimental effects such as myocardial infarction and cerebral hemorrhage in certain patients [1]. Therefore, many studies have been suggested to investigate ways to suppress the cardiovascular responses to tracheal intubation [1-3].

Based on an earlier study, $\mathrm{EC}_{95}$ of remifentanil to suppress cardiovascular responses during tracheal intubation was $6.0 \mathrm{ng} / \mathrm{mL}$ with an effect site propofol concentration of $3.4 \mu \mathrm{g} / \mathrm{mL}$ [4]. The time to reach the $6.0 \mathrm{ng} / \mathrm{mL}$ concentration of remifentanil is about 4 min at an infusion rate of $0.4 \mu \mathrm{g} / \mathrm{kg} / \mathrm{min}$ using Tivatrainer ${ }^{\circledR}$. There was a synergistic interaction between remifentanil and propofol with regard to hypnosis using response surface models [5-7]. Thus, the concentration of remifentanil required to achieve hypnosis can be reduced in the presence of propofol. Furthermore, when propofol is used to induce anesthesia, concomitant interaction of propofol and re-

${ }^{*}$ Corresponding author. mifentanil can cause hypotension after tracheal intubation, even if the cardiovascular response is prevented by propofol and remifentanil. The optimal dose of propofol and remifentanil induction to minimize the cardiovascular response associated with tracheal intubation may exist when both a single bolus of propofol and a continuous infusion of remifentanil are used for induction. Therefore, in the present study, we investigated the cardiovascular response associated with tracheal intubation when various dose combinations of propofol and continuous remifentanil infusion were used.

\section{Methods}

\subsection{Selection and Description of Patients}

This study was approved by the Ethics Committee of our institution, and informed consent was obtained from each patient. A prospective randomized comparative design was used. The study was conducted in a university hospital.

The sample size calculation was based on the assump- 
tion that a relative systolic blood pressure (BP) difference of $20 \mathrm{mmHg}$ would be detected. For a power of 0.8 and an $\alpha$ of 0.05 , a sample size of 17 patients in each group was calculated to be appropriate. Therefore, we collected 25 patients in each group to account for the possibility of exclusion data.

Seventy-five patients $23-80$ years of age with an American Society of Anesthesiologists physical status I or II who received scheduled general anesthesia were selected for the study. All patients received no premedication including opioids or sedatives before arriving in the operating room.

\subsection{Study Protocol}

Standard monitoring included electrocardiography, a noninvasive BP cuff, and a pulse oximeter. Patients received bicarbonate ringer solution $\left(\right.$ Bicarbon $^{\circledR}$; Ajinomoto Pharmaceutical Co. Ltd., Tokyo, Japan) at a rate of $10 \mathrm{~mL} / \mathrm{kg} / \mathrm{h}$ during the study period. All patients were randomly allocated to 1 of 3 groups: the R-0.4 P-1 group (remifentanil $0.4 \mu \mathrm{g} / \mathrm{kg} / \mathrm{min}$ and propofol $1 \mathrm{mg} / \mathrm{kg}$ ); the R-0.5 P-1 group (remifentanil $0.5 \mu \mathrm{g} / \mathrm{kg} / \mathrm{min}$ and propofol $1 \mathrm{mg} / \mathrm{kg}$ ); and the R-0.4 P-2 group (remifentanil 0.4 $\mu \mathrm{g} / \mathrm{kg} / \mathrm{min}$ and propofol $2 \mathrm{mg} / \mathrm{kg}$ ). As shown in the schema of times and study drug injection intervals in Figure 1, oxygen (6 L/min, 100\%) was delivered via a face mask for 1 min before general anesthesia was induced. Then a predetermined dose of remifentanil was started as a continuous infusion. One minute after remifentanil infusion, a predetermined dose of propofol was administered as a bolus. Rocuronium $1 \mathrm{mg} / \mathrm{kg}$ was injected following loss of consciousness 1 min after the propofol injection.

Tracheal intubation was performed 4 min after the start of remifentanil administration following controlled ventilation for 2 min with $2 \%$ sevoflurane. The infusion rate of remifentanil was decreased to $0.1 \mu \mathrm{g} / \mathrm{kg} / \mathrm{min}$ after intubation. We measured the non-invasive BP (HewlettPackard HP M1008B) and heart rate (HR, HewlettPackard HP M1001B) during this period until 5 min after tracheal intubation as baseline, at remifentanil administration, at propofol administration, at rocuronium administration, $1 \mathrm{~min}$ after rocuronium injection, before intubation, and $1 \mathrm{~min}, 2 \mathrm{~min}, 3 \mathrm{~min}, 4 \mathrm{~min}$, and $5 \mathrm{~min}$ after intubation. If the patients were not intubated in a trial or the time to intubation exceeded $60 \mathrm{~s}$, the data were excluded from the final analysis. If the systolic BP decreased to $<90 \mathrm{mmHg}$ during the study period, ephedrine $5 \mathrm{mg}$ was administered. If the HR decreased to $<50$ beats/min, atropine $0.5 \mathrm{mg}$ was administered.

\subsection{Statistical Analysis}

Statistical analysis was performed using the statistical software GraphPad Prism 5.0 (GraphPad Software, La Jolla, CA, USA). Data are presented as mean \pm SD. The $\mathrm{BP}$ and HR data were compared using one-way analysis of variance (ANOVA) and repeated-measures ANOVA followed by Bonferroni comparison. Demographic data were also analyzed using one-way ANOVA followed by the Newman-Keuls test. Values of $\mathrm{P}<0.05$ were considered statistically significant.

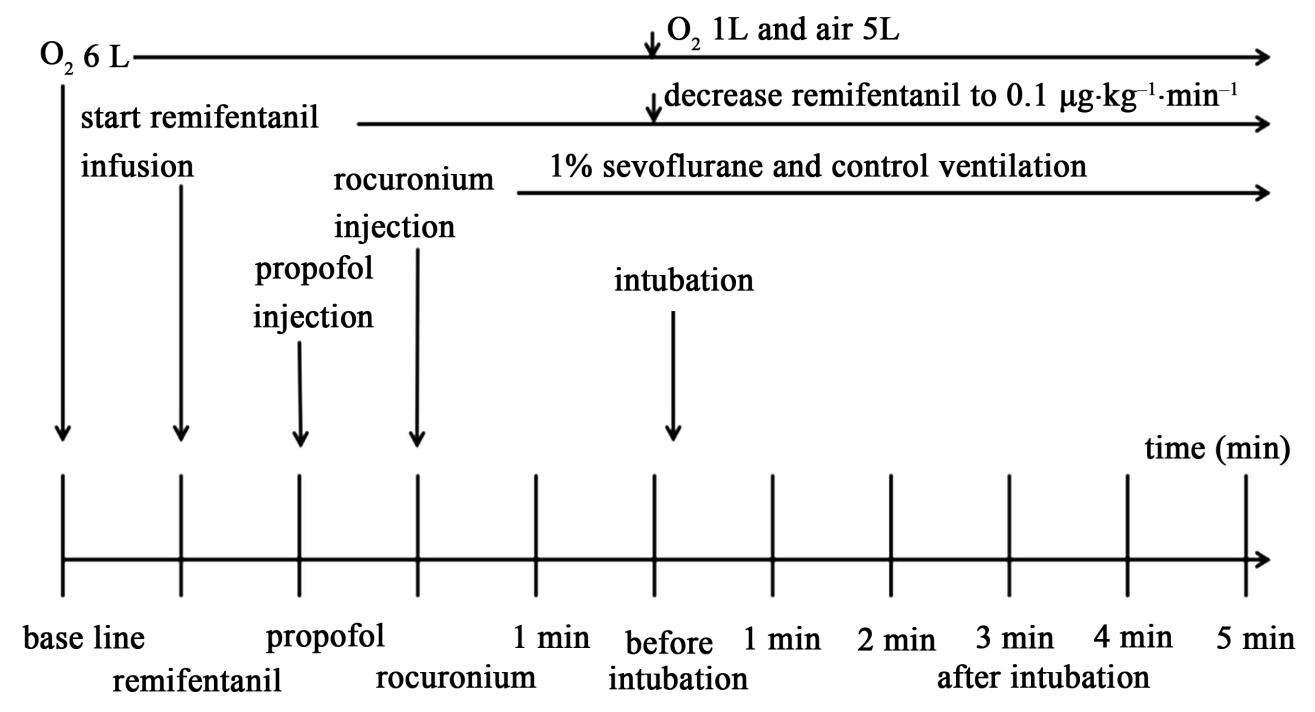

measurement points

Figure 1. Schematic study protocol. Measurement points included baseline, remifentanil, propofol, rocuronium, 1 min after rocuronium injection, before intubation, and $1 \mathrm{~min}, 2 \mathrm{~min}, 3 \mathrm{~min}, 4 \mathrm{~min}$, and $5 \mathrm{~min}$ after intubation. 


\section{Results}

\subsection{Demographic Data}

Patient demographics are presented in Table 1. One patient in the R-0.4 P-1 group was excluded from the study due to prolonged intubation time resulting from a difficult airway. Therefore, 24 patents in the R-0.4 P-1 group and 25 patients in the other groups were ultimately analyzed. All tracheal intubations were performed by TG or MY. There were no significant differences in age, height, weight, or intubation time. The number of the patients who were taking antihypertensive drugs was similar among the 3 groups.

\subsection{Blood Pressure}

Changes in systolic and diastolic BP are shown in Figure 2. Systolic BP in the R-0.4 P-1 group increased significantly $1 \mathrm{~min}$ after rocuronium injection, before intubation, and $1 \mathrm{~min}, 2 \mathrm{~min}, 3 \mathrm{~min}, 4 \mathrm{~min}$, and $5 \mathrm{~min}$ after intubation compared with the other 2 groups. Systolic BP at baseline was significantly different from that at rocuronium administration, $1 \mathrm{~min}$ after rocuronium injection, before intubation, and $3 \mathrm{~min}, 4 \mathrm{~min}$, and $5 \mathrm{~min}$ after intubation within the R-0.4 P-1 group. Systolic BP at baseline was significantly different from that at propofol administration, at rocuronium administration, 1 min after rocuronium injection, before intubation, and $1 \mathrm{~min}, 2 \mathrm{~min}$, $3 \mathrm{~min}, 4 \mathrm{~min}$, and $5 \mathrm{~min}$ after intubation within the R-0.4 P-2 group. Systolic BP at baseline was significantly different from that at rocuronium administration, 1 min after rocuronium injection, before intubation, and $1 \mathrm{~min}, 2 \mathrm{~min}$, $3 \mathrm{~min}, 4 \mathrm{~min}$, and $5 \mathrm{~min}$ after intubation within the R-0.5 P-1 group.

Table 1. Patients' demographic data, time for intubation and dose of ephedrine.

\begin{tabular}{cccc}
\hline & $\begin{array}{c}\text { R-0.4 P-1 } \\
\text { group } \\
(\mathrm{n}=24)\end{array}$ & $\begin{array}{c}\text { R-0.5 P-1 } \\
\text { group } \\
(\mathrm{n}=25)\end{array}$ & $\begin{array}{c}\text { R-0.4 P-2 } \\
\text { group } \\
(\mathrm{n}=25)\end{array}$ \\
\hline Age (year) & $64 \pm 15$ & $59 \pm 20$ & $62 \pm 13$ \\
Height (cm) & $156 \pm 7$ & $161 \pm 8$ & $159 \pm 9$ \\
Weight (kg) & $59 \pm 13$ & $63 \pm 11$ & $60 \pm 11$ \\
Male/female & $15 / 9$ & $13 / 12$ & $12 / 13$ \\
HT (number) & 14 & 11 & 14 \\
Time for intubation (sec) & $17 \pm 12$ & $21 \pm 16$ & $13 \pm 5$ \\
Dose of ephedrine (mg) & $0.8 \pm 1.9$ & $3.3 \pm 5.3$ & $5 \pm 4.5^{*}$ \\
\hline
\end{tabular}

R-0.4 P-1 group, remifentanil $0.4 \mathrm{~g} / \mathrm{k} / \mathrm{min}$ and propofol $1 \mathrm{mg} / \mathrm{kg}$; R-0.5 P-1 group, remifentanil $0.5 \mathrm{~g} / \mathrm{kg} / \mathrm{min}$ and propofol $1 \mathrm{mg} / \mathrm{kg}$; and R-0.4 P-2 group, remifentanil $0.4 \mathrm{~g} / \mathrm{kg} / \mathrm{min}$ and propofol $2 \mathrm{mg} / \mathrm{kg}$. HT = medicated antihypertensive drug. Values are mean $\pm \mathrm{SD}$. ${ }^{*} \mathrm{P}<0.05$ vs R-0.4 P-1 group.

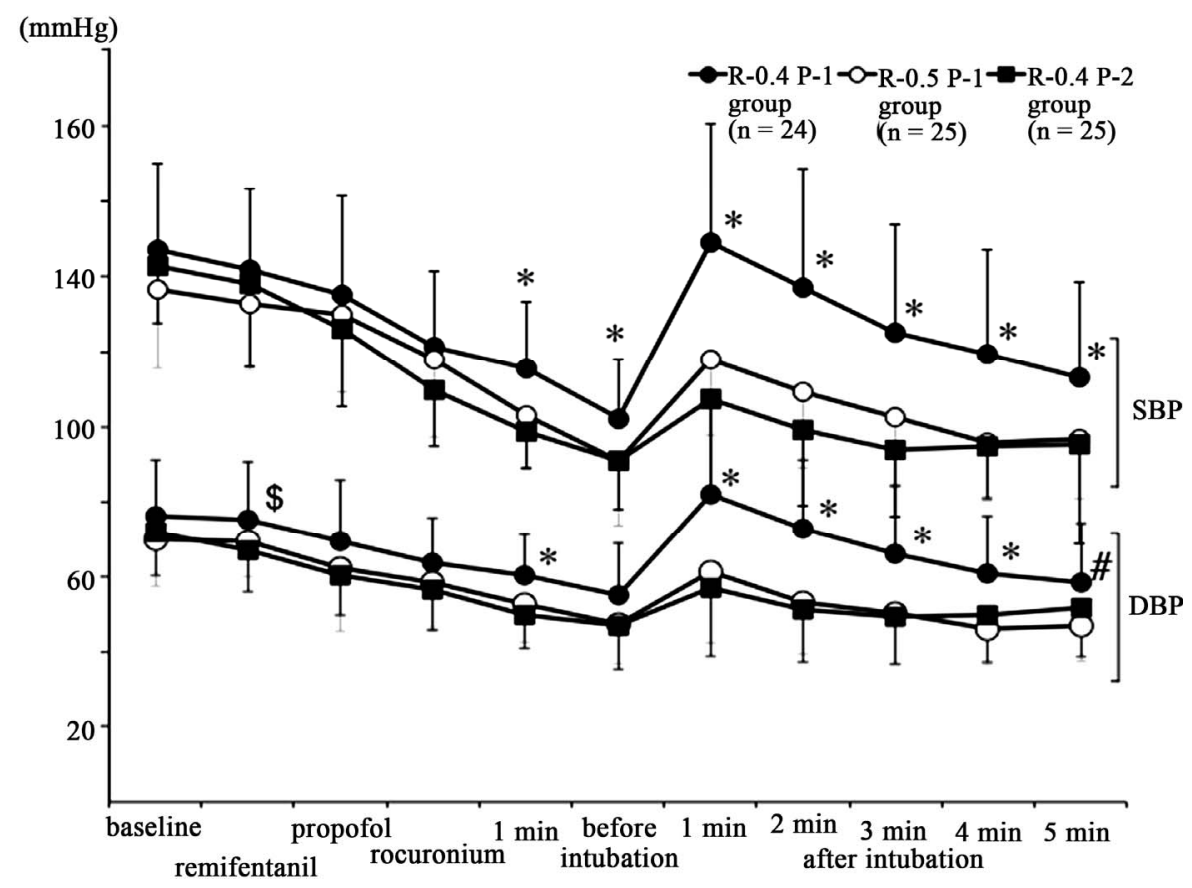

Figure 2. Changes of systolic and diastolic blood pressure. Systolic blood pressure is shown in the upper section and diastolic blood pressure is shown in the lower section. ${ }^{*} \mathrm{P}<0.05$ vs the other 2 groups, ${ }^{\$} \mathrm{P}<0.05$ vs $\mathbf{R - 0 . 4} \mathrm{P}-2$ group, ${ }^{\#} \mathrm{P}<0.05$ vs $\mathrm{R}-0.5$ P-1 group. Values are expressed as mean \pm SD. R-0.4 P-1 group, remifentanil $0.4 \mathrm{~g} / \mathrm{kg} / \mathrm{min}$ and propofol $1 \mathrm{mg} / \mathrm{kg} ; \mathrm{R}-0.5 \mathrm{P}-1$ group, remifentanil $0.5 \mu \mathrm{g} / \mathrm{kg} / \mathrm{min}$ and propofol $1 \mathrm{mg} / \mathrm{kg}$; and R-0.4 P-2 group, remifentanil $0.4 \mu \mathrm{g} / \mathrm{kg} / \mathrm{min}$ and propofol 2 $\mathrm{mg} / \mathrm{kg}$. 
Changes in diastolic BP are shown in Figure 2. Diastolic BP in the R-0.4 P-1 group was significantly increased at remifentanil administration, compared with the R-0.4 P-2 group, and at 1 min after rocuronium injection and $1 \mathrm{~min}, 2 \mathrm{~min}, 3 \mathrm{~min}, 4 \mathrm{~min}$, and $5 \mathrm{~min}$ after intubation compared with the other 2 groups. Diastolic BP at baseline differed significantly from that at rocuronium administration, $1 \mathrm{~min}$ after rocuronium injection, before intubation, and $3 \mathrm{~min}, 4 \mathrm{~min}$, and $5 \mathrm{~min}$ after intubation within the R-0.4 P-1 group. Diastolic BP at baseline was significantly different from that at rocuronium administration, 1 min after rocuronium injection, before intubation, and $1 \mathrm{~min}, 2 \mathrm{~min}, 3 \mathrm{~min}, 4 \mathrm{~min}$, and $5 \mathrm{~min}$ after intubation within the R-0.4 P-2 group. Diastolic BP at baseline differed significantly from that at rocuronium administration, $1 \mathrm{~min}$ after rocuronium injection, before intubation, and $2 \mathrm{~min}, 3 \mathrm{~min}, 4 \mathrm{~min}$, and $5 \mathrm{~min}$ after intubation within the R-0.5 P-1 group.

\subsection{Heart Rate}

Changes in HR are shown in Figure 3. HR in the R-0.4 P-1 group was significantly increased at 2 min after intubation compared with the R-0.4 P-2 group. HR at baseline was significantly different from that at $1 \mathrm{~min}$ after rocuronium injection, before intubation, and $4 \mathrm{~min}$ after intubation within the R-0.4 P-1 group. HR at baseline differed significantly from that before intubation and 1 min and 5 min after intubation within the R-0.4 P-2 group. HR at baseline was significantly different from that at 1 min after rocuronium injection, before intubation, and $4 \mathrm{~min}$ and $5 \mathrm{~min}$ after intubation within the R-0.5 P-1 group.

\subsection{Side Effects}

None of the patients developed airway complications during the study period. Doses of ephedrine in the R-0.4 P-2 group were larger than those in the R-0.4 P-1 group (Table 1).

\section{Discussion}

The findings of this study were that the changes in BP response due to tracheal intubation in the R-0.4 P-1 group were greater than those in the other 2 groups, the HR responses to tracheal intubation were similar among the 3 groups, and the required ephedrine doses in the R-0.4 P-2 group were larger than those in the other groups.

Earlier reports demonstrated that the required $\mathrm{EC}_{95}$ of remifentanil to suppress cardiovascular responses during tracheal intubation was $6.0 \mathrm{ng} / \mathrm{mL}$ with an effect site propofol concentration of $3.4 \mu \mathrm{g} / \mathrm{mL}$ [4]. According to the Tivatrainer ${ }^{\circledR}$, it takes about 4 min to reach an effect site concentration of $6.1 \mathrm{ng} / \mathrm{mL}$ using a continuous remifentanil infusion of $0.5 \mu \mathrm{g} / \mathrm{kg} / \mathrm{min}$ in a patient who is $160 \mathrm{~cm}$ tall, $60 \mathrm{~kg}$, and 60 years old. When a remifentanil infusion of $0.4 \mu \mathrm{g} / \mathrm{kg} / \mathrm{min}$ is started, the effect site concentration $4 \mathrm{~min}$ after infusion is $4.6 \mathrm{ng} / \mathrm{mL}$. Therefore,

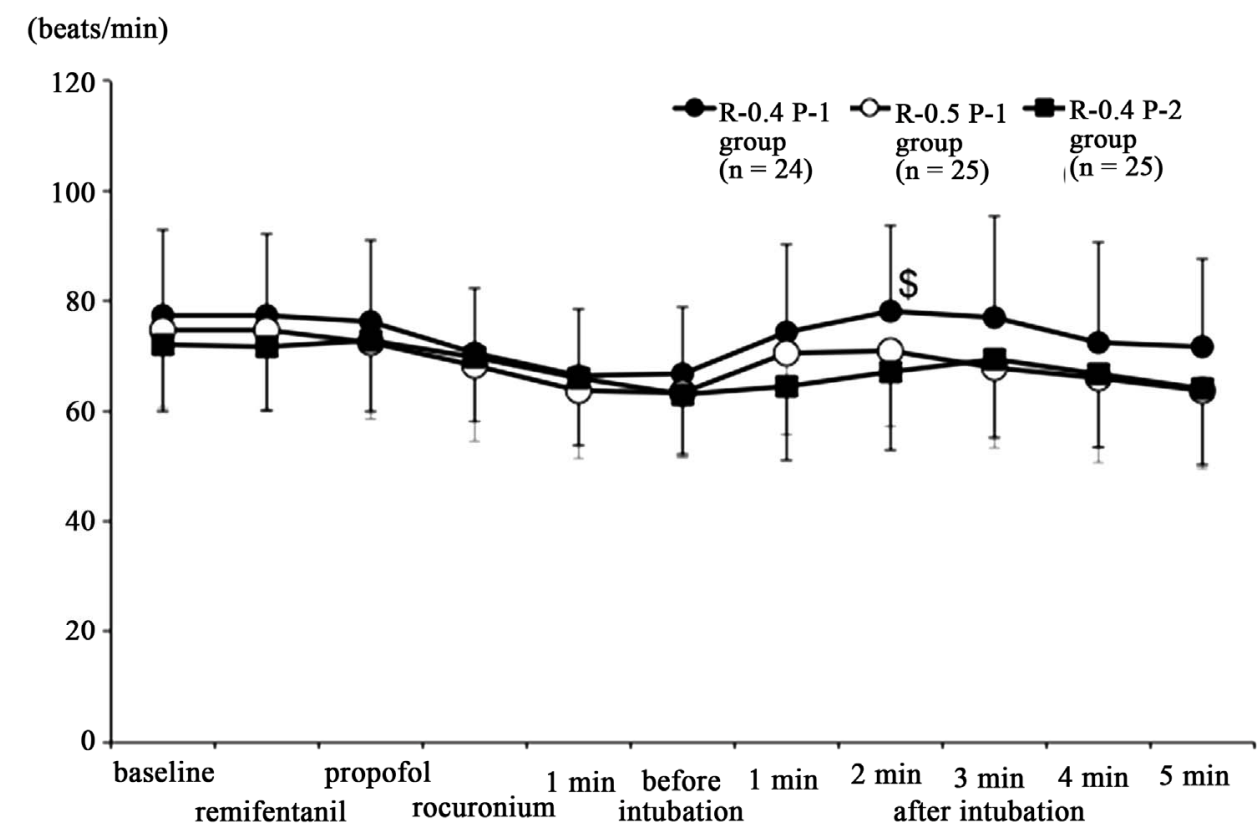

Figure 3. Changes in heart rate. ${ }^{{ }} \mathbf{P}<0.05$ vs R-0.4 P-2 group. Values are expressed as mean \pm SD. R-0.4 P-1 group, remifentanil $0.4 \mu \mathrm{g} / \mathrm{kg} / \mathrm{min}$ and propofol $1 \mathrm{mg} / \mathrm{kg} ; \mathrm{R}-0.5 \mathrm{P}-1$ group, remifentanil $0.5 \mu \mathrm{g} / \mathrm{kg} / \mathrm{min}$ and propofol $1 \mathrm{mg} / \mathrm{kg} ;$ and R-0.4 P-2 group, remifentanil $0.4 \mu \mathrm{g} / \mathrm{kg} / \mathrm{min}$ and propofol $2 \mathrm{mg} / \mathrm{kg}$. 
we intubated our patients 4 min after continuous remifentanil infusion in this study. The effect site concentrations of propofol at $3 \mathrm{~min}$ after the propofol bolus administration were 2.4 and $4.8 \mu \mathrm{g} / \mathrm{mL}$ at the dose of 1 $\mathrm{mg} / \mathrm{kg}$ and $2 \mathrm{mg} / \mathrm{kg}$, respectively, in a patient who was $160 \mathrm{~cm}$ tall, $60 \mathrm{~kg}$, and 60 years old using Tivatrainer ${ }^{\mathbb{R}}$. There will theoretically be a sufficient effect site concentration for tracheal intubation 4 min after continuous remifentanil infusion at the rate of $0.5 \mu \mathrm{g} / \mathrm{kg} / \mathrm{min}$ and $3 \mathrm{~min}$ after $2 \mathrm{mg} / \mathrm{kg}$ propofol injection. Therefore, we did not choose the combination of remifentanil $0.5 \mu \mathrm{g} / \mathrm{kg} / \mathrm{min}$ and propofol $2 \mathrm{mg} / \mathrm{kg}$, and we used the combination of R- 0.5 P-1, R-0.4 P-2, and R-0.4 P-1 in the present study to investigate the interaction between remifentanil and propofol.

There was a synergistic interaction between remifentanil and propofol concerning hypnosis using response surface models [5-7]. Thus, the required concentration of remifentanil to achieve hypnosis can be reduced in the presence of propofol. In this study, the changes in systolic BP in the R-0.4 P-1 group were greater than those in the R-0.4 P-2 group, suggesting that the addition of 1 $\mathrm{mg} / \mathrm{kg}$ propofol suppressed the pressure response to tracheal intubation. These combined suppressions of remifentanil and propofol cannot be ascribed to a synergistic interaction in this study.

Most reports concerning the pressure response to tracheal intubation in the presence of remifentanil used a bolus dose of propofol [8-13] or bolus followed by continuous infusion of remifentanil [14-16]. Miyake and colleagues demonstrated that continuous administration of remifentanil $0.5 \mu \mathrm{g} / \mathrm{kg} / \mathrm{min}$ with midazolam $0.2 \mathrm{mg} / \mathrm{kg}$ suppressed the pressure responses to tracheal intubation compared with remifentanil 0.1 and $0.2 \mu \mathrm{g} / \mathrm{kg} / \mathrm{min}$ [17] There were no significant differences in mean arterial pressure between continuous infusion of remifentanil 0.5 $\mu \mathrm{g} / \mathrm{kg} / \mathrm{min}$ following a bolus dose of remifentanil $1 \mu \mathrm{g} / \mathrm{kg}$ and $0.25 \mu \mathrm{g} / \mathrm{kg} / \mathrm{min}$ following a bolus dose of $0.5 \mu \mathrm{g} / \mathrm{kg}$. They used the propofol $0.5 \mathrm{mg} / \mathrm{kg}$ followed by $10 \mathrm{mg}$ every $10 \mathrm{~s}$ until loss of verbal contact. The present results are consistent with the suppression of remifentanil 0.5 $\mu \mathrm{g} / \mathrm{kg} / \mathrm{min}$ shown by Miyake et al. but are not consistent with the report by Hall et al. that infusion of remifentanil $0.25 \mu \mathrm{g} / \mathrm{kg} / \mathrm{min}$ suppressed the pressure response to tracheal intubation [18]. The reason for the suppression by low-dose remifentanil seems to be the use of $1 \%$ isoflurane and $67 \%$ nitrous oxide [18].

There were no differences in HR changes among the 3 groups except at one point in the R-0.4 P-1 group. This result suggests that no combination of remifentanil and propofol affects the changes in HR response to tracheal intubation. This result was consistent with that of an earlier report [19].
In this study, the time for tracheal intubation did not differ among the 3 groups. The earlier report demonstrated that a long time for tracheal intubation could lead to an increased pressure response to tracheal intubation [20]. Thus, the influence of the required time for tracheal intubation could be minimized in this study.

There are some considerable limitations of the present study. First, we measured BP using noninvasive monitoring. This method raises the possibility of over- and underestimation of large BP changes during tracheal intubation. Although it took only about $20 \mathrm{~s}$ to measure BP in this study, invasive BP monitoring should be used to measure exact BP changes. Second, patients who were taking antihypertensives were included in the 3 groups. Hypertensive patients have exaggerated cardiovascular responses to laryngoscopy and tracheal intubation and are susceptible to episodes of hypotension after the induction of anesthesia [21-23]. Therefore, changes in cardiovascular response to laryngoscopy and tracheal intubation in some hypertensive patients might be large. Because the distribution of hypertensive patients in the present 3 groups was equal, these effects might be negligible. Further study is needed to clarify the effects of hypertension on responses to tracheal intubation using this regime. Third, aging also could affect the cardiovascular response to laryngoscopy and tracheal intubation [24]. We had a large variation in age from 23 to 80 years old, whereas the mean age was similar among the 3 groups. This effect might also be negligible because the age distribution was similar among the 3 groups.

In conclusion, when the combination of continuous remifentanil and bolus propofol infusion was used, the combination use of remifentanil $0.4 \mu \mathrm{g} / \mathrm{kg} / \mathrm{min}$ and propofol $1 \mathrm{mg} / \mathrm{kg}$ led to an exaggerated cardiovascular response to laryngoscopy and tracheal intubation compared to the combination of remifentanil $0.5 \mu \mathrm{g} / \mathrm{kg} / \mathrm{min}$ and propofol $1 \mathrm{mg} / \mathrm{kg}$ or remifentanil $0.4 \mu \mathrm{g} / \mathrm{kg} / \mathrm{min}$ and propofol $2 \mathrm{mg} / \mathrm{kg}$. The combination of remifentanil and propofol exhibited an interaction that suppressed the cardiovascular response to laryngoscopy and tracheal intubation.

\section{REFERENCES}

[1] A. L. Kovac, "Controlling the Hemodynamic Response to Laryngoscopy and Endotracheal Intubation," Journal of Clinical Anesthesia, Vol. 8, No. 1, 1996, pp. 63-79. doi:10.1016/0952-8180(95)00147-6

[2] N. Bruder, D. Ortega and C. Granthil, "Consequences and Prevention Methods of Hemodynamic Changes during Laryngoscopy and Intratracheal Intubation," Annales Françaises Danesthèsie et de Reanimation, Vol. 11, No. 1, 1992, pp. 57-71. doi:10.1016/S0750-7658(05)80321-1

[3] J. Horak and S. Weiss, "Emergent Management of the 
Airway. New Pharmacology and the Control of Comorbidities in Cardiac Disease, Ischemia, and Valvular Heart Disease," Critical Care Clinics, Vol. 16, No. 3, 2000, pp. 411-427. doi:10.1016/S0749-0704(05)70120-2

[4] A. Albertin, A. Casati, L. Federica, V. Roberto, V. Travaglini, P. Bergonzi and G. Torri, "The Effect-Site Concentration of Remifentanil Blunting Cardiovascular Responses to Tracheal Intubation and Skin Incision during Bispectral Index-Guided Propofol Anesthesia," Anesthesia and Analgesia, Vol. 101, No. 1, 2005, pp. 125-130. doi:10.1213/01.ANE.0000153012.35120.FE

[5] M. J. Mertens, E. Olofsen, F. H. Engbers, A. G. Burm, J. G. Bovill and J. Vuyk, "Propofol Reduces Perioperative Remifentanil Requirements in a Synergistic Manner: Response Surface Modeling of Perioperative RemifentanilPropofol Interactions," Anesthesiology, Vol. 99, No. 3, 2003, pp. $347-359$.

doi:10.1097/00000542-200308000-00016

[6] T. W. Bouillon, J. Bruhn, L. Radulescu, C. Andresen, T. J. Shafer, C. Cohane and S. L. Shafer, "Pharmacodynamic Interaction between Propofol and Remifentanil Regarding Hypnosis, Tolerance of Laryngoscopy, Bispectral Index, and Electroencephalographic Approximate Entropy," Anesthesiology, Vol. 100, No. 6, 2004, pp. 1353-1372. doi:10.1097/00000542-200406000-00006

[7] S. E. Kern, G. Xie, J. L. White and T. D. Egan, "A Response Surface Analysis of Propofol-Remifentanil Pharmacodynamic Interaction in Volunteers," Anesthesiology, Vol. 100, No. 6, 2004, pp. 1373-1381. doi:10.1097/00000542-200406000-00007

[8] Q. Y. Yang, F. S. Xue, X. Liao, H. P. Liu, M. P. Luo, Y. C. Xu, Y. Liu and Y. M. Zhang, "Comparison of Bolus Remifentanil versus Bolus Fentanyl for Blunting Cardiovascular Intubation Responses in Children: A Randomized, Double-Blind Study," Chinese Medical Journal, Vol. 122, No. 1, 2009, pp. 44-50

[9] X. Liao, Q. Y. Yang, F. S. Xue, M. P. Luo, Y. C. Xu, Y. Liu and Y. M. Zhang, "Bolus Dose Remifentanil and Sufentanil Blunting Cardiovascular Intubation Responses in Children: A Randomized, Double-Blind Comparison," European Journal of Anaesthesiology, Vol. 26, No. 1, 2009, pp. 73-80. doi:10.1097/EJA.0b013e32831a6b2f

[10] S. Mohammadreza and H. Azim, "Tracheal Intubation without Muscle Relaxants: A Randomized Study of Remifentanil or Alfentanil in Combination with Thiopental," Annals of Saudi Medicine, Vol. 28, No. 2, 2008, pp. 89-95. doi:10.4103/0256-4947.51746

[11] F. S. Xue, Y. C. Xu, Y. Liu, Q. Y. Yang, X. Liao, K. P. Liu, C. W. Li and H. T. Sun, "Different Small-Dose Remifentanil Blunting the Cardiovascular Response to Laryngoscopy and Intubation in Children: A Randomized Double-Blind Comparison," European Journal of Anaesthesiology, Vol. 25, No. 2, 2008, pp. 106-112. doi: $10.1017 / \mathrm{S} 026502150700261 \mathrm{X}$

[12] U. M. Klemola, S. Mennander and L. Saarnivaara, "Tracheal Intubation without the Use of Muscle Relaxants: Remifentanil or Alfentanil in Combination with Propofol," Acta Anaesthesiologica Scandinavica, Vol. 44, No. 4, 2000, pp. 465-469. doi:10.1034/j.1399-6576.2000.440419.x

[13] B. Y. Park, C. W. Jeong, E. A. Jang, S. J. Kim, S. T. Jeong, M. H. Shin, J. Lee and K. Y. Yoo, "Dose-Related Attenuation of Cardiovascular Responses to Tracheal Intubation by Intravenous Remifentanil Bolus in Severe Pre-Eclamptic Patients Undergoing Caesarean Delivery," British Journal of Anaesthesia, Vol. 106, No. 1, 2011, pp. 82-87. doi:10.1093/bja/aeq275

[14] A. M. Maguire, N. Kumar, J. L. Parker, D. J. Rowbotham and J. P. Thompson, "Comparison of Effects of Remifentanil and Alfentanil on Cardiovascular Response to Tracheal Intubation in Hypertensive Patients," British Journal of Anaesthesia, Vol. 86, No. 1, 2001, pp. 90-93. doi:10.1093/bja/86.1.90

[15] A. S. Habib, J. L. Parker, A. M. Maguire, D. J. Rowbotham and J. P. Thompson, "Effects of Remifentanil and Alfentanil on the Cardiovascular Responses to Induction of Anaesthesia and Tracheal Intubation in the Elderly," British Journal of Anaesthesia, Vol. 88, No. 3, 2002, pp. 430-433. doi:10.1093/bja/88.3.430

[16] Z. Salihoglu, S. Demiroluk and Y. Kose, "Comparison of Effects of Remifentanil, Alfentanil and Fentanyl on Cardiovascular Responses to Tracheal Intubation in Morbidly Obese Patients," European Journal of Anaesthesiology, Vol. 19, No. 2, 2002, pp. 125-128.

[17] W. Miyake, Y. Oda, Y. Ikeda, K. Tanaka, S. Hagihira, H. Iwaki and A. Asada, "Effect of Remifentanil on Cardiovascular and Bispectral Index Responses Following the Induction of Anesthesia with Midazolam and Subsequent Tracheal Intubation," Journal of Anesthesia, Vol. 24, No. 2, 2010, pp. 161-167. doi:10.1007/s00540-010-0895-4

[18] A. P. Hall, J. P. Thompson, N. A. Leslie, A. J. Fox, N. Kumar and D. J. Rowbotham, "Comparison of Different Doses of Remifentanil on the Cardiovascular Response to Laryngoscopy and Tracheal Intubation," British Journal of Anaesthesia, Vol. 84, No. 1, 2000, pp. 100-102. doi:10.1093/oxfordjournals.bja.a013362

[19] T. P. Chaves, J. M. Gomes, F. E. Pereira, S. L. Cavalcante, I. M. Leitão, H. S. Monte and R. D. Escalant, "Hemodynamic and Metabolic Evaluation of Dexmedetomidine and Remifentanil Continuous Infusion in Videolaparoscopic Cholecystectomy: Comparative Study," Revista Brasileira de Anestesiologia, Vol. 53, No. 4, 2003 , pp. 419-430. doi:10.1590/S0034-70942003000400001

[20] R. K. Stoelting, "Circulatory Changes during Direct Laryngoscopy and Tracheal Intubation: Influence of Duration of Laryngoscopy with or without Prior Lidocaine," Anesthesiology, Vol. 47, No. 4, 1977, pp. 381-384. doi:10.1097/00000542-197710000-00012

[21] C. Prys-Roberts, L. T. Greene, R. Meloche and P. Foëx, "Studies of Anaesthesia in Relation to Hypertension. II. Haemodynamic Consequences of Induction and Endotracheal Intubation," British Journal of Anaesthesia, Vol. 43, No. 6, 1971, pp. 531-547. doi:10.1093/bja/43.6.531

[22] K. Y. Yoo, C. W. Jeong, W. M. Kim, H. K. Lee, S. Jeong, S. J. Kim, H. B. Bae, D. Y. Lim and S. S. Chung, "Cardiovascular and Arousal Responses to Single-Lumen Endotracheal and Double-Lumen Endobronchial Intubation 
in the Normotensive and Hypertensive Elderly," Korean Journal of Anesthesiology, Vol. 60, No. 2, 2011, pp. 9097. doi:10.4097/kjae.2011.60.2.90

[23] S. Kihara, J. Brimacombe, Y. Yaguchi, S. Watanabe, N. Taguchi and T. Komatsuzaki, "Hemodynamic Responses among Three Tracheal Intubation Devices in Normotensive and Hypertensive Patients," Anesthesia and Analge- sia, Vol. 3, No. 3, 2003, pp. 890-895. doi:10.1213/01.ANE.0000048706.15720.C9

[24] L. M. Van Bortel and J. J. Spek, "Influence of Aging on Arterial Compliance," Journal of Human Hypertension, Vol. 12, No. 9, 1998, pp. 583-586.

doi:10.1038/sj.jhh.1000669 